\title{
Developmental pathways and programming of diabetes: epidemiological aspects
}

\author{
Johan G Eriksson 1,2,3 \\ 1Department of General Practice and Primary Health Care, University of Helsinki and Helsinki University Hospital, Helsinki, Finland \\ ${ }^{2}$ Folkhälsan Research Center, University of Helsinki, Helsinki, Finland \\ 3Department of Obstetrics and Gynecology, National University of Singapore, Yong Loo Lin School of Medicine, Singapore, Singapore
}

Correspondence should be addressed to J G Eriksson: johan.eriksson@helsinki.fi

This paper is part of a thematic section on 30 Years of the Developmental Endocrinology of Health and Disease. The guest editors for this section were Sean Limesand, Kent Thornburg and Jane Harding

\begin{abstract}
Type 2 diabetes (T2D) is a major, rapidly increasing global public health challenge. The major risk factors for T2D include overweight and obesity, lifestyle-related factors and genetic factors. Early life exposures shape the developmental trajectories and alter susceptibility to T2D. Based on epidemiological studies it has been suggested that fetal undernutrition plays a role in the etiology of T2D. A low birth weight has been considered a proxy for fetal undernutrition. A meta-analysis reported that a $1 \mathrm{~kg}$ increase in birth weight is associated with a roughly $20 \%$ lower risk of T2D. Although fetal life is of major importance for future health, the period spanning the first 1000 days of life, is characterized by great plasticity and largely influencing later health. Different growth trajectories during this time period have also been associated with an increased risk of T2D. Studies assessing the association between age at BMI rebound in childhood and later risk for T2D have reported a fivefold difference in T2D according to age at BMI rebound. Developmental and epidemiological cohort studies focusing on T2D have major public health implications supporting a paradigm shift; a shift from focusing upon risk factor modification in adult life to adopting a life course perspective when studying T2D. This paradigm shift will not only help us in getting a better understanding of the pathophysiology underlying T2D, but it will also open new possibilities and opportunities in the prevention of T2D and related disorders.
\end{abstract}
Key Words
- diabetes
- obesity
- development
- DOHaD

\section{Type 2 diabetes}

Type 2 diabetes (T2D) is a major, rapidly increasing global public health challenge. The number of adults with diabetes is estimated to have increased from 108 to 422 million between 1980 and 2014 making it one of the fastest growing diseases worldwide. The corresponding age-standardized diabetes prevalence increased from 4.3 to $9.0 \%$ in men and from 5.0 to $7.9 \%$ in women between
1980 and 2014, respectively. It has been estimated that if current trends continue, there will be over 700 million people with diabetes before 2030. This increase is due to an increasing prevalence of the disease, an increasing global population size as well as longer life expectancy (International Diabetes Federation 2015, NCD Risk Factor Collaboration 2016, Rosengren 2018). Traditionally T2D 
used to be a disease of the elderly, but today people develop T2D at a younger age, which increases its impact on overall life course health.

Hyperglycemia, the characteristic feature and diagnostic criteria for diabetes, is not the major problem associated with the disease. Macrovascular and microvascular complications commonly associated with T2D form a huge disease burden. A major comorbidity of diabetes is cardiovascular disease (CVD), estimated to affect at least one-third of all individuals with diabetes. Because of the close association between diabetes and $\mathrm{CVD}$, the rise in diabetes prevalence will have a huge impact on global health and also largely contribute to the increased cost of treating diabetes and diabetesrelated comorbidities (Grover et al. 2015, Shah et al. 2015, Rosengren 2018).

Better knowledge of risk factors for T2D and the disease process has improved treatment outcomes. Obviously new therapeutic agents have played a role. Consequently, the prognosis of T2D has improved greatly both in relation to overall mortality and morbidity and overall social burden (Hu et al. 2001, Emerging Risk Factors Collaboration 2010, Peters et al. 2014, Zinman et al. 2015, Gæde et al. 2016, Marso et al. 2016, Bommer et al. 2017, Rawshani et al. 2018, von Bonsdorff et al. 2018). The major risk factors of T2D include overweight and obesity, lifestylerelated factors and genetic factors. However, T2D is a multifactorial disorder and early life exposures shape the developmental trajectories and alter susceptibility to T2D, besides the traditional risk factors. Despite the fact that the hyperglycemia encountered in overweight people is commonly termed T2D the disease entity includes several different phenotypes, with hyperglycemia being the common feature, as described by Ahlqvist and coworkers (Ahlqvist et al. 2018).

The relationship between globally increasing rates of T2D parallels the increasing rise in adiposity but it is not straightforward (NCD Risk Factor Collaboration 2016, 2017). One in four adults in the United Kingdom is obese while the corresponding number in the USA is one in three. However, prevalence estimates for T2D are much lower than those for obesity, being $6.6 \%$ and $8.2 \%$ in men and $4.9 \%$ and $6.4 \%$ in women, in the United Kingdom and the United States, respectively. Similar modest increase in T2D prevalence has been reported from other countries despite a rapid increase in obesity prevalence. Interestingly, in China, T2D prevalence is high despite a relatively low degree of obesity (Chan et al. 2009, Ng et al . 2013, Abraham et al. 2015, Norhammar et al. 2016, Read et al. 2016). The underlying reasons for this discrepancy

(C) 2019 Society for Endocrinology Published by Bioscientifica Ltd. Printed in Great Britain are not readily apparent. Genetic susceptibility has been proposed to be an underlying reason as well as a body composition predisposing to metabolic diseases despite a low BMI in several Asian populations. Prenatally and postnatally acting factors including nutrition, growth and developmental trajectories also play important roles. In fact, non-optimal prenatal growth and nutrition combined with an excess of calories in childhood and in adult life could explain part of the contemporary epidemic of T2D in several Asian countries (Hales \& Barker 1992, Zimmet et al. 2014, Yin et al. 2016, Krishnaveni et al. 2017).

The objective of this review is to discuss epidemiological evidence of early life exposures and developmental trajectories and their associations with T2D in later life (Table 1). Potential underlying mechanisms explaining the associations will not be discussed in greater details.

\section{Body size at birth and type 2 diabetes in adult life}

The concept that disease risk can pass across generations is not new, nor is the idea that factors active during early phases of life might be of major importance in determining later health. The latter was a concept already emphasized by Hippocrates (Jones 1868).

Already in the 1930s some of the first suggestions that early life events might have long-term effects on future health and disease risk were put forward in a more scientific way (Kermack et al. 1934). In the early 1970s Dörner and coworkers proposed that both preand postnatal conditions were related to later risk of arteriosclerosis. Dörner has also been given credit for introducing the term 'programming' in this field (Dörner 1973, Dörner et al. 1973). Programming can be defined as a consequence of a stimulus or insult during a critical time period inducing permanent changes in the structure and function of the developing tissues and organs. Another pioneer in this field was a Norwegian general practitioner Anders Forsdahl who in 1977 pointed out that there were relationships between early life conditions and the risks of CVD in later life (Forsdahl 1977). From a historical point of view the 'fuel-mediated teratogenesis' hypothesis put forward by Freinkel needs be mentioned. In this hypothesis Freinkel tried to explain how the metabolic state of the mother could influence her offspring's risk for diabetes and other health outcomes (Freinkel 1980). In 1985 based upon findings from the UK national birth cohort, it was reported that birth weight was inversely related to blood pressure (Wadsworth et al. 1985). 
Table 1 Developmental pathways and programming of type 2 diabetes.

\begin{tabular}{l}
\hline Key points \\
\hline Early life exposures shape developmental trajectories and \\
alter susceptibility to type 2 diabetes \\
Both a small and a large body size at birth influence the \\
future risk for type 2 diabetes \\
Different growth trajectories during infancy have been \\
associated with type 2 diabetes \\
An early age of adiposity rebound is associated with an \\
increased risk for type 2 diabetes \\
Adopting a life course perspective when studying type 2 \\
diabetes will help us in getting a better understanding of the \\
underlying pathophysiology and open new possibilities for \\
prevention of type 2 diabetes
\end{tabular}

However, these observations were not discussed or taken any further by the researchers. Similar to Forsdahl's observations in Norway, a Finnish study linked poverty in childhood with increased risk of CVD in adult life (Notkola et al. 1985).

In 1986, David Barker and coworkers reported on a correlation between the geographical distribution of infant mortality and CVD in adulthood in the United Kingdom, also suggesting that early life factors and CVD have a common denominator. These publications were soon followed by more publications by Barker and his group (Barker \& Osmond 1986, 1988, Barker et al. 1989, 1990).

Despite the previous findings reporting on an inverse association between birth size and CVD in adulthood the scientific diabetes community was stunned when Hales and Barker in 1991 reported an inverse association between birth weight and risk of developing T2D and/or impaired glucose tolerance (IGT) (Hales et al. 1991). In fact, hardly anybody was ready to believe in these findings. Obesity was one of the best documented risk factors for T2D and the findings from the Hertfordshire study did not fit into this paradigm. This first piece of evidence showed that among 468 men born in Hertfordshire, UK, who were studied at a mean age of 64 years, the highest risk for impairment in glucose regulation was seen among men with the lowest birth weight and lowest weight at 1 year. The effect sizes were impressive: those men born with a birth weight $\leq 2495 \mathrm{~g}$ had an OR of 6.6 (CI 95\% 1.5-28) compared to the reference group with a birth weight $>4309 \mathrm{~g}$. Men with previously known diabetes were excluded from the study and the analysis were adjusted for adult BMI. In the same study, it was also shown that blood pressure was inversely related to birth weight.

Based on the epidemiological studies and findings by David Barker and the Southampton group, it was suggested that fetal undernutrition would be important in the etiology of T2D - as well as in many other noncommunicable diseases (NCDs). Maternal undernutrition was suggested to be one major underlying cause leading to fetal undernutrition. In 1990 Barker put forward what has later been called the 'Barker hypothesis' proposing that intrauterine growth retardation, leading to a small body size at birth, has a causal relationship to the origins of hypertension, coronary heart disease and T2D. This hypothesis has also been called the Hales's hypothesis, the Fetal Origins of Adult Disease (FOAD) hypothesis and the thrifty phenotype hypothesis. Further development and deeper understanding around the importance of programming of health and disease has led to the development of the Developmental Origins of Health and Disease (DOHaD) hypothesis.

However, critical voices were raised opposing the findings by Barker and coworkers, suggesting that the findings could be largely due to confounding by socioeconomic status or by a biased sample selection. It is well known that lower socioeconomic status is associated with a higher prevalence of obesity, T2D as well as a smaller body size at birth. Further it was well known that gestational diabetes is associated with a larger birth weight or macrosomia but at the same time with an increased risk for T2D. In a study conducted in 1179 American Indians who had an oral glucose tolerance test done between 20 and 39 years of age it was shown that the prevalence of T2D was greatest in those with the lowest and highest birth weights. In other words, the association between birth weight and T2D was U-shaped in the Pima Indians. The association of T2D with high birth weight was largely explained by the presence of maternal diabetes during pregnancy (McCance et al. 1994).

It is a well-known fact that T2D has a genetic component and one interesting proposal was put forward by James Neel already in the early 1960s (Neel 1962). He hypothesized that a 'thrifty genotype' could be the underlying cause of the rapid increase in T2D and other NCDs. This genotype enabled storage of surplus energy primarily as fats during periods of plentiness and gave survival advantages during famines but would obviously become detrimental in societies characterized by continuous energy supply. The 'fetal insulin' hypothesis proposed that shared genetic variants inherited by the fetus could affect both fetal growth and predispose to adult disease including T2D (Hattersley \& Tooke 1999). This is still today, 20 years later, an area of active research (Horikoshi et al. 2016, Beaumont et al. 2017). More studies are needed to disentangle the shared environmental, 
genetic and social factors that lead to small body size at birth and predispose to T2D later in life.

The attitude within the research community toward the 'Barker hypothesis' changed largely after findings from the United States and more precisely findings based on 69,526 women in the Nurses' Health Study who had self-reported data on birth weight. It was reported that birth weight was inversely associated with T2D in adulthood (Rich-Edwards et al. 1999). Further adjustment for ethnicity, socioeconomic status in childhood and adult lifestyle factors did not substantially alter the associations. Based on findings from the same large cohort of women, an inverse association between birth weight and CVD had previously been reported (Rich-Edwards et al. 1997). Further, numerous animal studies have supported the 'Barker hypothesis' by demonstrating an independent effect of slow growth in utero and T2D in adult life. These animal studies were another major reason why the scientific community began to accept the hypothesis.

Findings reporting an inverse association between body size at birth and T2D have later been replicated in tens of studies and in several different populations around the globe. A systematic review published in 2008 examined the evidence on the association between birth weight and T2D in adults - primarily based upon epidemiological studies (Whincup et al. 2008). The pooled OR for T2D was 0.75-0.78 per kilogram increase in birth weight depending on factors adjusted for. Adjustment for current BMI strengthened the association, while adjustment for socioeconomic status had little influence on the findings. In other words, a $1 \mathrm{~kg}$ increase in birth weight was associated with a roughly $20 \%$ lower risk of T2D. However, in some populations, primarily native North American populations a U-shaped association was acknowledged.

A more recent systematic review and meta-analysis including 21 studies involving over 300,000 people and over 20,000 cases with T2D showed similar findings as the systematic review by Whincup et al. (Whincup et al. 2008). Compared with those with a birth weight between 2500 and $4000 \mathrm{~g}$ those born with a birth weight $<2500 \mathrm{~g}$ had an OR for T2D of 1.41 (95\% CI: 1.26-1.58). High birth weight was not statistically significantly associated with an increased risk for T2D (OR=1.11, 95\% CI: 1.00-1.24) in the more recent meta-analysis, although the trend was similar to the findings by Whincup and coworkers (Whincup et al. 2008, Zhao et al. 2018).

Birth weight is certainly a crude measurement of newborn size. However, the strong epidemiological findings suggest that factors active during prenatal life, and potentially influencing birth weight can have a lifelong influence on future health. A question of major importance to ask is why is a small birth weight associated with later adverse health outcomes? However, not only birth weight but also other measures of body size at birth like for example ponderal index, BMI and birth length have been associated with later health outcomes. The effects of body size at birth on future health occur across the entire range of birth sizes and is not a consequence of small body size at birth only. Interestingly, based on findings from the Netherlands, it has been shown that maternal malnutrition during gestation may permanently affect adult health in the offspring, even without affecting birth size of the newborn (Roseboom et al. 2001, de Rooij et al. 2006).

\section{Growth in childhood and T2D in adult life}

Although fetal life is of major importance for the future health, the first 1000 days of life, in other words, the time period spanning from conception until end of infancy or 2 years of age is characterized by great plasticity and is therefore an important period of opportunity for the foundations of health and development.

Based upon a large number of epidemiological studies, we know that the risk of T2D is increased in people who were born small. It is generally assumed that this increased risk for T2D among people born with a low birth weight is associated with increased adiposity in adult life. However, it is not obvious when the weight gain and increased adiposity predisposing to T2D takes place. Is it in infancy, in childhood or in adult life? Longitudinal studies spanning over decades are needed to determine this and answer the question.

In a longitudinal register-based study including 8760 subjects born 1934 to 1944, in Helsinki, Finland, and belonging to the Helsinki Birth Cohort Study (HBCS), who had on average 18 measurements of height and weight between birth and 12 years of age, the association between early growth and T2D was assessed. Those who later developed T2D had a small body size at birth and were small during infancy, compared to those in the cohort who did not develop T2D. However, after infancy, their weights and BMIs rose to exceed the average of that of the study cohort.

Since T2D is a heterogenous disorder, one could assume that there are several pathways leading to what we call T2D. There are several pathways potentially leading to a small body size at birth, including shorter gestation 
and slow fetal growth. However, little data are available in the literature focusing upon the impact of these different pathways on the heterogeneity of T2D.

Two pathways of infant and childhood growth that lead to T2D have been identified in HBCS. These were defined by dividing the study cohort into two groups according to median birth weights (i.e. $3500 \mathrm{~g}$ ). Those with birth weights below $3500 \mathrm{~g}$ catched-up toward the average in height and weight soon after birth. Around 2 years of age, those who later developed T2D, began to gain weight more rapidly than the other children, they also reached weights and BMIs that were above the average for the cohort. In another group of children with birth weights below $3500 \mathrm{~g}$, the linear growth of those children who developed T2D in adulthood faltered during early infancy. Around 2 years of age, their rate of gain in weight and BMI became more rapid than that of the other children in this group, and they also reached weights and BMIs that were above the group average (Eriksson et al. 2003a). The clinical T2D phenotypes in adult life also differ between these two groups.

Similar findings have been reported based upon a clinical study including 2003 people aged 61 years with growth data from birth throughout childhood from the HBCS cohort. Subjects with T2D and/or IGT were identified with a 2 -h $75 \mathrm{~g}$ oral glucose tolerance test. Consistent with findings from larger epidemiological cohorts both IGT and T2D were associated with low birth weight. The risk was further increased in those who had a low weight gain during infancy; a 1 s.D. increase in weight at 2 years was associated with a $24 \%$ lower risk for either IGT or T2D. A rapid increase in BMI between 2 and 11 years was associated with an increased risk for T2D (Eriksson et al. 2006).

Similar findings as those reported in the HBCS have been described in a longitudinal study from India, in the New Delhi Birth Cohort, including 1492 men and women aged 26-32 years at the time of the study and who grew up at a time of rapid nutritional transition. Those who later developed T2D or IGT, which was $>15 \%$ of the study cohort, typically had a low BMI during infancy followed by an accelerated increase in BMI until adult life. Those individuals who developed impaired glucose regulation were not overweight in childhood, but later became overweight due to an accelerated gain in weight that started already in childhood (Bhargava et al. 2004).

Several patterns of growth during childhood have been associated with higher risk of T2D as well as with metabolic markers (e.g. adiposity, inflammatory markers and elevated blood pressure) associated with an increased risk of T2D. A recent meta-analysis, based on 17 studies, reported an OR for overweight/obesity of 3.66 (95\% CI 2.59-5.17) in the presence of rapid weight gain before 2 years. The ORs being even higher when weight gain occurred before 1 year (Zheng et al. 2018). However, study findings in relation to the impact of rapid weight gain during infancy in relation to metabolic proxies and risk factors for T2D have been highly inconsistent (Forsén et al. 2000, Eriksson et al. 2003a, 2006, 2015, Barker 2005, Leunissen et al. 2009, Larnkjaer et al. 2010, FabriciusBjerre et al. 2011, Zheng et al. 2018).

Long-term longitudinal studies, like HBCS, have been criticized for being historical cohorts - which is certainly true. However, long-term follow-up studies are needed to be able to assess the true risk for T2D; also because T2D is a disorder associated with increasing age. Therefore, studies only assessing obesity and risk factors for T2D cannot provide hard outcomes. Further it is known that long-term consequences of childhood obesity can be largely modified by body size in adult life (Bjerregaard et al. 2018). Therefore, overreaching conclusions based on studies applying intermediate outcomes cannot and should not be made.

\section{Timing of adiposity or BMI rebound and T2D}

BMI is commonly used as a proxy for adiposity, although not an optimal one, because, similarly to birth weight, it does not distinguish between fat and lean body mass. BMI is strongly and positively associated with T2D and related metabolic outcomes. However, not all obese people will develop T2D something clearly shown by the huge difference in prevalence of obesity and T2D in many populations. In addition to the previously discussed periods in early life associated with T2D, the timing of adiposity or BMI rebound needs to be acknowledged in relation to development of $\mathrm{T} 2 \mathrm{D}$.

In 1984 Rolland-Cacchera and coworkers proposed the term adiposity rebound to describe the increase in adiposity that occurs in children after infancy (RollandCachera et al. 1984). In children there is usually a rapid increase in BMI during the first year of life, it then subsequently declines and reaches a minimum at around 4-6 years of age. BMI rebound is defined as the age after infancy at which BMI starts to rise again, and this is typically around 4-6 years of age. Rolland-Cacchera and coworkers demonstrated a relationship between age at adiposity rebound and adiposity at age 16 years. An early age at adiposity rebound has also been associated 
with obesity and the metabolic syndrome in adulthood (Péneau et al. 2016, Giudici et al. 2017).

Due to the importance of overweight and obesity as risk factors for T2D, some studies have also been assessing the association between age at BMI rebound and later risk for T2D. In the study by Bhargava and coworkers, it was shown that those individuals who developed IGT/T2D showed an early age at BMI rebound and an accelerated increase in BMI until adulthood. Interestingly, mean BMI at the time of BMI rebound was similar in those with IGT/T2D and in those with normal glucose tolerance. Only mean age at BMI rebound was significantly lower (6.3 years vs 6.7 years) in the group that developed IGT/T2D. Also the prevalence of IGT/T2D fell with an increasing age at time of BMI rebound. Those children with the youngest age at BMI rebound ( $\leq 5$ years) had the highest BMI in later childhood which persisted into adulthood. Further they were characterized by thinness at birth and thinness throughout infancy (Bhargava et al. 2004).

These reported findings from the Delhi cohort are similar to findings from HBCS 1934-44 cohort. Those who developed T2D had an early age at BMI rebound and an accelerated gain in weight and BMI, but not in height. In the HBCS cohort $<1 \%$ of the children were obese according to today's standard. Similar to the findings in the Delhi cohort an early age at BMI rebound was associated with low weight and BMI at age 1 year. There was an almost fivefold difference in T2D prevalence according to age at BMI rebound; those with a BMI rebound $<5$ years of age had a T2D prevalence of $8.6 \%$, while the corresponding number in those with a BMI rebound after 7 years was 1.8\% (Eriksson et al. 2003b).

Both maternal and paternal factors seem to influence age at BMI rebound. Maternal obesity has been associated with an 11.4 months earlier age at BMI rebound, while the corresponding number for paternal obesity was 6.5 months earlier (Aris et al. 2018).

From a public health and preventive point of view the identification of factors associated with an early age at BMI rebound might be important as well as the identification of individuals with a young age at BMI rebound. Based on epidemiological studies the underlying explanations can only be speculated upon but certainly include genetic, epigenetic, environmental and lifestyle-related factors.

\section{Maternal obesity, gestational diabetes and T2D in the offspring}

The original hypothesis put forward by David Barker suggested that maternal undernutrition during pregnancy will influence fetal growth and consequently offspring body size at birth and modify later health outcomes. There are still globally too many regions where pregnant women suffer from undernutrition, but nutritional excess is also becoming a problem. Obesity is a considerable global health issue also among pregnant women. Within the European Union (EU) about one-third of women of childbearing age are overweight and every fifth is obese. A high maternal BMI is associated with several pregnancy complications (Norman \& Reynolds 2011).

There is increasing evidence suggesting that maternal adiposity also programs several long-term health outcomes in the offspring (Godfrey et al. 2017). Maternal obesity is strongly associated with obesity in the offspring, and this association seems to be stronger for maternal than it is for paternal obesity, suggesting that it is not only due to a common genetic background. Further, maternal obesity is known to increase the risk of cardiovascular events and premature mortality among the offspring. A higher maternal BMI is also associated with an increased risk of T2D (Godfrey et al. 2017). Findings from HBCS showed that the associations with T2D and maternal BMI during pregnancy were stronger in women (Eriksson et al. 2014).

Obesity is one major risk factor for gestational diabetes (GDM). GDM is known to have adverse shortand long-term effects on the pregnant woman and her child, both during pregnancy and later in life. Fetal exposure to maternal hyperglycemia is a major risk factor for impairment in glucose regulation in later life (Fetita et al. 2006, Malcolm 2012, Mitanchez et al. 2015).

The mechanisms explaining these findings, both in relation to maternal adiposity and GDM, probably include mechanisms associated with overnutrition of the fetus. As a consequence of maternal overweight and obesity glucose, insulin and free fatty acid concentrations are usually elevated (Godfrey et al. 2017). This can result in programming of the developing fetus, making it more vulnerable to several obesity-related health outcomes. There are other potential underlying mechanisms including environmental, genetic and epigenetic mechanisms (Ramsay et al. 2002, Catalano et al. 2006, Gluckman \& Hanson 2008).

\section{Conclusions and implications for future research}

What can we learn from developmental and epidemiological cohort studies focusing on T2D? One important lesson with major public health implications 
is that there should be a paradigm shift; a shift from focusing upon risk factor modification in adult life to adopting a life course perspective when studying T2D and other NCDs. This paradigm shift will not only help us in getting a better understanding of the pathophysiology underlying T2D, but it will also open new possibilities and opportunities in the prevention of $\mathrm{T} 2 \mathrm{D}$ and related disorders.

Why is body size at birth associated with later disease risk? According to the original hypothesis put forward by David Barker malnutrition during critical phases in prenatal life could have permanent effects on the structure and function on several body systems, including skeletal muscle, liver, kidneys and pancreas. This process often called fetal programming results in a 'thrifty phenotype', which is programmed to preserve brain growth and optimize immediate survival at the expense of other organs of 'less immediate importance'. Growth comprised organs cannot compensate later in life when exposed to excess nutrition, the consequences being hyperglycemia, dyslipidemia, elevated blood pressure and related metabolic consequences.

A small body size at birth is associated with at least two classical features of T2D, namely insulin resistance and an impairment in insulin secretion, the latter being largely due to the presence of a smaller pancreas with fewer insulin producing beta-cells (Snoeck et al. 1990). A small body size at birth is also associated with a smaller muscle mass in adult life and a higher body fat percentage, another characteristic predisposing to insulin resistance and T2D (Ylihärsilä et al. 2007). The possibilities to modify body size at birth are small; however, based on epidemiological studies we have been able to recognize several developmental pathways during childhood that are associated with an increased risk for future disease, including T2D, hypertension and chronic kidney disease. This increased knowledge should be used to plan and initiate preventive efforts early in the life course. These preventive measures will primarily be based upon lifestyle modification and will not target only T2D but a large number of other NCDs.

Today it is commonly agreed that the DOHaD concept should be viewed as part of a larger biological mechanism of developmental plasticity. Plasticity enables the organism, in response to various cues to adapt and modify its phenotype to the prevailing environment. These adaptations may be of immediate benefit or they can aim at prediction of future environment. Present evidence suggests that the plastic phase in humans extends from conception for at least during the first 2 years of life or the first 1000 days of life. Theoretically plasticity provides the developing organism with the capacity to respond to changes in environment; this has also been called predictive adaptive responses. In case the prognosis goes wrong and there is a mismatch between the predicted future and the real future, disease risk increases. For the prediction to be accurate the environment should remain the same from conception to adulthood. However, in the world of today there is commonly a 'mismatch' between prenatal environment and postnatal environment associated with overnutrition and lifestyles predisposing to several NCDs including T2D. Interestingly, theoretically if an individual born small remains small throughout the life course a small body size at birth is not necessarily associated with markedly increased adverse health outcomes in later life. However, if there is a mismatch between body size at birth and body size attained later in childhood the risk for adverse health outcomes increase.

There is now growing evidence suggesting that the effects of programming may also manifest in future generations without any further exposure. In other words the existence of transgenerational effects, by which an early life exposure may affect the health also of future generations, has been proposed and reported (Gluckman et al. 2010, Aiken \& Ozanne 2014, Bygren et al. 2014). The most plausible underlying mechanisms explaining this phenomenon are epigenetic ones.

\section{Declaration of interest}

The author declares that there is no conflict of interest that could be perceived as prejudicing the impartiality of this review.

\section{Funding}

This work did not receive any specific grant from any funding agency in the public, commercial or not-for-profit sector.

\section{References}

Abraham TM, Pencina KM, Pencina MJ \& Fox CS 2015 Trends in diabetes incidence: the Framingham Heart Study. Diabetes Care 38 482-487. (https://doi.org/10.2337/dc14-1432)

Ahlqvist E, Storm P, Käräjämäki A, Martinell M, Dorkhan M, Carlsson A, Vikman P, Prasad RB, Aly DM, Almgren P, et al. 2018 Novel subgroups of adult-onset diabetes and their association with outcomes: a data-driven cluster analysis of six variables. Lancet: Diabetes and Endocrinology 6 361-369. (https://doi.org/10.1016/S22138587(18)30051-2)

Aiken CE \& Ozanne SE 2014 Transgenerational developmental programming. Human Reproduction Update 20 63-75. (https://doi. org/10.1093/humupd/dmt043)

Aris IM, Rifas-Shiman SL, Li LJ, Kleinman K, Coull BA, Gold DR, Hivert MF, Kramer MS \& Oken E 2018 Pre-, perinatal, and parental (c) 2019 Society for Endocrinology Published by Bioscientifica Ltd. Printed in Great Britain 
predictors of body mass index trajectory milestones. Journal of Pediatrics 2018201 69.e8-77.e8. (doi:10.1016/j.jpeds.2018.05.041)

Barker DJ 2005 The developmental origins of insulin resistance. Hormone Research 64 (Supplement 3) 2-7.

Barker DJ \& Osmond C 1986 Infant mortality, childhood nutrition, and ischaemic heart disease in England and Wales. Lancet 1 1077-1081.

Barker DJ \& Osmond C 1988 Low birth weight and hypertension. BMJ 297 134-135.

Barker DJ, Osmond C, Golding J, Kuh D \& Wadsworth ME 1989 Growth in utero, blood pressure in childhood and adult life, and mortality from cardiovascular disease. BMJ 298 564-567. (https://doi. org/10.1136/bmj.298.6673.564)

Barker DJ, Winter PD, Osmond C, Margetts B \& Simmonds SJ 1989 Weight in infancy and death from ischaemic heart disease. Lancet 2 577-580. (https://doi.org/10.1016/S0140-6736(89)90710-1)

Barker DJ, Bull AR, Osmond C \& Simmonds SJ 1990 Fetal and placental size and risk of hypertension in adult life. BMJ 301 259-262. (https:// doi.org/10.1136/bmj.301.6746.259)

Beaumont RN, Horikoshi M, McCarthy MI \& Freathy RM 2017 How can genetic studies help us to understand links Between birth weight and type 2 diabetes? Current Diabetes Reports 17 22. (https://doi org/10.1007/s11892-017-0852-9)

Bhargava SK, Sachdev HS, Fall CH, Osmond C, Lakshmy R, Barker DJ, Biswas SK, Ramji S, Prabhakaran D \& Reddy KS 2004 Relation of serial changes in childhood body-mass index to impaired glucose tolerance in young adulthood. New England Journal of Medicine 350 865-875. (https://doi.org/10.1056/NEJMoa035698)

Bjerregaard LG, Jensen BW, Ängquist L, Osler M, Sørensen TIA \& Baker JL 2018 Change in overweight from childhood to early adulthood and risk of type 2 diabetes. New England Journal of Medicine $\mathbf{3 7 8}$ 1302-1312. (https://doi.org/10.1056/NEJMoa1713231)

Bommer C, Heesemann E, Sagalova V, Manne-Goehler J, Atun R, Bärnighausen T \& Vollmer S 2017 The global economic burden of diabetes in adults aged 20-79 years: a cost-of-illness study. Lancet: Diabetes and Endocrinology 5 423-430. (https://doi.org/10.1016/S22138587(17)30097-9)

Bygren LO, Tinghög P, Carstensen J, Edvinsson S, Kaati G, Pembrey ME \& Sjöström M 2014 Change in paternal grandmothers' early food supply influenced cardiovascular mortality of the female grandchildren. BMC Genetics 15 12. (https://doi.org/10.1186/1471-2156-15-12)

Catalano PM \& Ehrenberg HM 2006 The short- and long-term implications of maternal obesity on the mother and her offspring. BJOG 113 1126-1133. (https://doi.org/10.1111/j.14710528.2006.00989.x)

Chan JC, Malik V, Jia W, Kadowaki T, Yajnik CS, Yoon KH \& Hu FB 2009 Diabetes in Asia: epidemiology, risk factors, and pathophysiology. JAMA 301 2129-2140. (https://doi.org/10.1001/jama.2009.726)

Dörner G 1973 Die mögliche Bedeutung der prä und/oder perinatalen Ernährung fur die Pathogenese der Obesitas. Acta Biologica and Medica Germanica 30 19-22.

Dörner G, Haller K \& Leonhardt M 1973 Zur möglichen Bedeutung der prä- und/oder fruh postnatalen Ernährung fur die Pathogenese der Arterioskleroze. Acta Biologica and Medica Germanica 31 31-35.

Emerging Risk Factors Collaboration, Sarwar N, Gao P, Seshasai SR, Gobin R, Kaptoge S, Di Angelantonio E, Ingelsson E, Lawlor DA, Selvin E, et al. 2010 Diabetes mellitus, fasting blood glucose concentration, and risk of vascular disease: a collaborative metaanalysis of 102 prospective studies. Lancet $\mathbf{3 7 5}$ 2215-2222. (https:// doi.org/10.1016/S0140-6736(10)60484-9)

Eriksson JG, Forsén T, Tuomilehto J, Osmond C \& Barker DJP 2003a Early adiposity rebound in childhood and risk of type 2 diabetes in adult life. Diabetologia 46 190-194. (https://doi.org/10.1007/s00125-0021012-5)

Eriksson JG, Forsen TJ, Osmond C \& Barker DJ 2003b Pathways of infant and childhood growth that lead to type 2 diabetes. Diabetes Care $\mathbf{2 6}$ 3006-3010. (https://doi.org/10.2337/diacare.26.11.3006)
Eriksson JG, Kajantie E, Lampl M \& Osmond C 2015 Trajectories of body mass index amongst children who develop type 2 diabetes as adults. Journal of Internal Medicine 278 219-226. (https://doi.org/10.1111/ joim.12354)

Eriksson JG, Osmond C, Kajantie E, Forsén TJ \& Barker DJ 2006 Patterns of growth among children who later develop type 2 diabetes or its risk factors. Diabetologia 49 2853-2858. (https://doi.org/10.1007/ s00125-006-0459-1)

Eriksson JG, Sandboge S, Salonen MK, Kajantie E \& Osmond C 2014 Long-term consequences of maternal overweight in pregnancy on offspring later health: findings from the Helsinki Birth Cohort study. Annals of Medicine 46 434-438. (https://doi.org/10.3109/07853890.2 014.919728)

Fabricius-Bjerre S, Jensen RB, Faerch K, Larsen T, Molgaard C, Michaelsen KF, Vaag A \& Greisen G 2011 Impact of birth weight and early infant weight gain on insulin resistance and associated cardiovascular risk factors in adolescence. PLOS ONE 6 e20595. (https://doi.org/10.1371/journal.pone.0020595)

Fetita LS, Sobngwi E, Serradas P, Calvo F \& Gautier JF 2006 Consequences of fetal exposure to maternal diabetes in offspring. Journal of Clinical Endocrinology and Metabolism 91 3718-3724. (https://doi.org/10.1210/ jc.2006-0624)

Forsén T, Eriksson J, Tuomilehto J, Reunanen A, Osmond C \& Barker D 2000 The fetal and childhood growth of persons who develop type 2 diabetes. Annals of Internal Medicine 133 176-182. (https://doi. org/10.7326/0003-4819-133-3-200008010-00008)

Freinkel N 1980 Banting lecture 1980. Of pregnancy and progeny. Diabetes 29 1023-1035.

Forsdahl A 1977 Are poor living conditions in childhood and adolescence an important risk factor for arteriosclerotic heart disease? British Journal of Preventive and Social Medicine 31 91-95.

Gæde P, Oellgaard J, Carstensen B, Rossing P, Lund-Andersen H, Parving HH \& Pedersen O 2016 Years of life gained by multifactorial intervention in patients with type 2 diabetes mellitus and microalbuminuria: 21 years follow-up on the Steno-2 randomised trial. Diabetologia 59 2298-2307. (https://doi.org/10.1007/s00125-016-4065-6)

Giudici KV, Rolland-Cachera MF, Gusto G, Goxe D, Lantieri O, Hercberg S \& Péneau S 2017 Body mass index growth trajectories associated with the different parameters of the metabolic syndrome at adulthood. International Journal of Obesity 41 1518-1525. (https://doi. org/10.1038/ijo.2017.119)

Gluckman PD \& Hanson MA 2008 Developmental and epigenetic pathways to obesity: an evolutionary-developmental perspective. International Journal of Obesity 32 (Supplement 7) S62-S71. (https:// doi.org/10.1038/ijo.2008.240)

Gluckman PD, Hanson MA \& Buklijas T 2010 A conceptual framework for the developmental origins of health and disease. Journal of Developmental Origins of Health and Disease 1 6-18. (https://doi. org/10.1017/S2040174409990171)

Godfrey KM, Reynolds RM, Prescott SL, Nyirenda M, Jaddoe VW, Eriksson JG \& Broekman BF 2017 Influence of maternal obesity on the long-term health of offspring. Lancet: Diabetes and Endocrinology 5 53-64. (https://doi.org/10.1016/S2213-8587(16)30107-3)

Grover SA, Kaouache M, Rempel P, Joseph L, Dawes M, Lau DC \& Lowensteyn I 2015 Years of life lost and healthy life-years lost from diabetes and cardiovascular disease in overweight and obese people: a modelling study. Lancet: Diabetes and Endocrinology 3 114-122. (https://doi.org/10.1016/S2213-8587(14)70229-3)

Hales CN \& Barker DJ 1992 Type 2 (non-insulin-dependent) diabetes mellitus: the thrifty phenotype hypothesis. Diabetologia 35 595-601. (https://doi.org/10.1007/BF00400248)

Hales CN, Barker DJ, Clark PM, Cox LJ, Fall C, Osmond C \& Winter PD 1991 Fetal and infant growth and impaired glucose tolerance at age 64. BMJ 303 1019-1022. (https://doi.org/10.1136/bmj.303.6809.1019)

Hattersley AT \& Tooke JE 1999 The fetal insulin hypothesis: an alternative explanation of the association of low birthweight with diabetes and https://joe.bioscientifica.com

https://doi.org/10.1530/JOE-18-0680 (c) 2019 Society for Endocrinology Published by Bioscientifica Ltd. Printed in Great Britain 
vascular disease. Lancet 353 1789-1792. (https://doi.org/10.1016/ S0140-6736(98)07546-1)

Horikoshi M, Beaumont RN, Day FR, Warrington NM, Kooijman MN, Fernandez-Tajes J, Feenstra B, van Zuydam NR, Gaulton KJ, Grarup N, et al. 2016 Genome-wide associations for birth weight and correlations with adult disease. Nature 538 248-252. (https://doi. org/10.1038/nature19806)

Hu FB, Stampfer MJ, Solomon CG, Liu S, Willett WC, Speizer FE, Nathan DM \& Manson JE 2001 The impact of diabetes mellitus on mortality from all causes and coronary heart disease in women: 20 years of follow-up. Archives of Internal Medicine 161 1717-1723. (https://doi.org/10.1001/archinte.161.14.1717)

International Diabetes Federation 2015 IDF Diabetes Atlas, 7th ed. Brussels, Belgium: International Diabetes Federation.

Jones WHS 1868 Hippocrates Collected Works I. Cambridge, MA, USA: Harvard University Press.

Kermack W, McKendrick A \& McKinlay P 1934 Death rates in Great Britain and Sweden: some general regularities and their significance. Lancet 30 698-703.

Krishnaveni GV \& Yajnik CS 2017 Developmental origins of diabetes-an Indian perspective. European Journal of Clinical Nutrition 71 865-869. (https://doi.org/10.1038/ejcn.2017.87)

Larnkjaer A, Schack-Nielsen L, Molgaard C, Ingstrup HK, Holst JJ \& Michaelsen KF 2010 Effect of growth in infancy on body composition, insulin resistance, and concentration of appetite hormones in adolescence. American Journal of Clinical Nutrition 91 1675-1683. (https://doi.org/10.3945/ajcn.2009.27956)

Leunissen RW, Kerkhof GF, Stijnen T \& Hokken-Koelega A 2009 Timing and tempo of first-year rapid growth in relation to cardiovascular and metabolic risk profile in early adulthood. JAMA 301 2234-2242. (https://doi.org/10.1001/jama.2009.761)

Malcolm J 2012 Through the looking glass: gestational diabetes as a predictor of maternal and offspring long-term health. Diabetes/ Metabolism Research and Reviews 28 307-311. (https://doi.org/10.1002/ dmrr.2275)

Marso SP, Daniels GH, Brown-Frandsen K, Kristensen P, Mann JF, Nauck MA, Nissen SE, Pocock S, Poulter NR, Ravn LS, et al. 2016 Liraglutide and cardiovascular outcomes in type 2 diabetes. New England Journal of Medicine 375 311-322. (https://doi.org/10.1056/ NEJMoa1603827)

McCance DR, Pettitt DJ, Hanson RL, Jacobsson LT, Knowler WC \& Bennett PH 1994 Birth weight and non-insulin dependent diabetes: thrifty genotype, thrifty phenotype, or surviving small baby genotype? BMJ 308 942-945. (https://doi.org/10.1136/ bmj.308.6934.942)

Mitanchez D, Yzydorczyk C, Siddeek B, Boubred F, Benahmed M \& Simeoni U 2015 The offspring of the diabetic mother - short- and long-term implications. Best Practice and Research Clinical Obstetrics and Gynaecology 29 256-269.

von Bonsdorff MB, von Bonsdorff ME, Haanpää M, Salonen M, Mikkola TM, Kautiainen H \& Eriksson JG 2018 Work-loss years among people diagnosed with diabetes: a reappraisal from a life course perspective. Acta Diabetologica 55 485-491. (https://doi.org/10.1007/ s00592-018-1119-x)

NCD Risk Factor Collaboration (NCD-RisC) 2016 Worldwide trends in diabetes since 1980: a pooled analysis of 751 population-based studies with 4.4 million participants. Lancet 387 1513-1530. (https://doi. org/10.1016/S0140-6736(16)00618-8)

NCD Risk Factor Collaboration (NCD-RisC) 2017 Worldwide trends in body-mass index, underweight, overweight, and obesity from 1975 to 2016: a pooled analysis of 2416 population-based measurement studies in 128.9 million children, adolescents, and adults. Lancet 390 2627-2642. (https://doi.org/10.1016/S0140-6736(17)32129-3)

Neel JV 1962 Diabetes mellitus: a 'thrifty' genotype rendered detrimental by 'progress'? American Journal of Human Genetics 14 353-362.
Ng M, Fleming T, Robinson M, Thomson B, Graetz N, Margono C, Mullany EC, Biryukov S, Abbafati C, Abera SF, et al. 2014 Global, regional, and national prevalence of overweight and obesity in children and adults during 1980-2013: a systematic analysis for the Global Burden of Disease study 2013. Lancet 384 766-781. (https:// doi.org/10.1016/S0140-6736(14)60460-8)

Norhammar A, Bodegard J, Nystrom T, Thuresson M, Eriksson JW \& Nathanson D 2016 Incidence, prevalence and mortality of type 2 diabetes requiring glucose-lowering treatment, and associated risks of cardiovascular complications: a nationwide study in Sweden, 2006-2013. Diabetologia 59 1692-1701. (https://doi.org/10.1007/s00125-016-3971-y)

Norman JE \& Reynolds RM 2011 The consequences of obesity and excess weight gain in pregnancy. Proceedings of the Nutrition Society $\mathbf{7 0}$ 450-456. (https://doi.org/10.1017/S0029665111003077)

Notkola V, Punsar S, Karvonen MJ \& Haapakoski J 1985 Socio-economic conditions in childhood and mortality and morbidity caused by coronary heart disease in adulthood in rural Finland. Social Science and Medicine 21 517-523. (https://doi.org/10.1016/02779536(85)90035-8)

Péneau S, González-Carrascosa R, Gusto G, Goxe D, Lantieri O, Fezeu L, Hercberg S \& Rolland-Cachera MF 2016 Age at adiposity rebound: determinants and association with nutritional status and the metabolic syndrome at adulthood. International Journal of Obesity $\mathbf{4 0}$ 1150-1156. (https://doi.org/10.1038/ijo.2016.39)

Peters SA, Huxley RR \& Woodward M 2014 Diabetes as risk factor for incident coronary heart disease in women compared with men: a systematic review and meta-analysis of 64 cohorts including 858,507 individuals and 28,203 coronary events. Diabetologia 57 1542-1551. (https://doi.org/10.1007/s00125-014-3260-6)

Ramsay JE, Ferrell WR, Crawford L, Wallace AM, Greer IA \& Sattar N 2002 Maternal obesity is associated with dysregulation of metabolic, vascular, and inflammatory pathways. Journal of Clinical Endocrinology and Metabolism 87 4231-4237. (https://doi.org/10.1210/jc.2002-020311)

Rawshani A, Rawshani A, Franzén S, Sattar N, Eliasson B, Svensson AM, Zethelius B, Miftaraj M, McGuire DK, Rosengren A, et al. 2018 Risk factors, mortality, and cardiovascular outcomes in patients with type 2 diabetes. New England Journal of Medicine 379 633-644. (https://doi. org/10.1056/NEJMoa1800256)

Read SH, Kerssens JJ, McAllister DA, Colhoun HM, Fischbacher CM, Lindsay RS, McCrimmon RJ, McKnight JA, Petrie JR, Sattar N, et al. 2016 Trends in type 2 diabetes incidence and mortality in Scotland between 2004 and 2013. Diabetologia 59 2106-2113. (https://doi. org/10.1007/s00125-016-4054-9)

Rich-Edwards JW, Stampfer MJ, Manson JE, Rosner B, Hankinson SE, Colditz GA, Willett WC \& Hennekens CH 1997 Birth weight and risk of cardiovascular disease in a cohort of women followed up since 1976. BMJ 315 396-400. (https://doi.org/10.1136/bmj.315.7105.396)

Rich-Edwards JW, Colditz GA, Stampfer MJ, Willett WC, Gillman MW, Hennekens CH, Speizer FE \& Manson JE 1999 Birthweight and the risk for type 2 diabetes mellitus in adult women. Annals of Internal Medicine 130 278-284. (https://doi.org/10.7326/0003-4819-130-4_ Part 1-199902160-00005)

Rolland-Cachera MF, Deheeger M, Bellisle F, Sempé M, GuilloudBataille M \& Patois E 1984 Adiposity rebound in children: a simple indicator for predicting obesity. American Journal of Clinical Nutrition 39 129-135. (https://doi.org/10.1093/ajcn/39.1.129)

de Rooij SR, Painter RC, Phillips DI, Osmond C, Michels RP, Godsland IF, Bossuyt PM, Bleker OP \& Roseboom TJ 2006 Impaired insulin secretion after prenatal exposure to the Dutch famine. Diabetes Care 29 1897-1901. (https://doi.org/10.2337/dc06-0460)

Roseboom TJ, van der Meulen JH, Ravelli AC, Osmond C, Barker DJ \& Bleker OP 2001 Effects of prenatal exposure to the Dutch famine on adult disease in later life: an overview. Molecular and Cellular Endocrinology 185 93-98. (https://doi.org/10.1016/S03037207(01)00721-3) https://joe.bioscientifica.com

https://doi.org/10.1530/JOE-18-0680
(C) 2019 Society for Endocrinology Published by Bioscientifica Ltd. Printed in Great Britain 
Rosengren A 2018 Cardiovascular disease in diabetes type 2: current concepts. Journal of Internal Medicine 284 240-253. (https://doi. org/10.1111/joim.12804)

Shah AD, Langenberg C, Rapsomaniki E, Denaxas S, Pujades-Rodriguez M, Gale CP, Deanfield J, Smeeth L, Timmis A \& Hemingway H 2015 Type 2 diabetes and incidence of cardiovascular diseases: a cohort study in 1.9 million people. Lancet: Diabetes and Endocrinology 3 105-113. (https://doi.org/10.1016/S2213-8587(14)70219-0)

Snoeck A, Remacle C, Reusens B \& Hoet JJ 1990 Effect of a low protein diet on the fetal rat pancreas. Biology of the Neonate 50 107-118.

Wadsworth ME, Cripps HA Midwinter RE \& Colley JR 1985 Blood pressure in a national birth cohort at the age of 36 related to social and familial factors, smoking, and body mass. BMJ 291 1534-1538.

Whincup PH, Kaye SJ, Owen CG, Huxley R, Cook DG, Anazawa S, BarrettConnor E, Bhargava SK, Birgisdottir BE, Carlsson S, et al. 2008 Birth weight and risk of type 2 diabetes: a systematic review. JAMA $\mathbf{3 0 0}$ 2886-2897. (https://doi.org/10.1001/jama.2008.886)

Yin J, Kong AP \& Chan JC 2016 Prevention and care programs addressing the growing prevalence of diabetes in China. Current Diabetes Reports 16 130. (https://doi.org/10.1007/s11892-016-0821-8)
Ylihärsilä H, Kajantie E, Osmond C, Forsén T, Barker DJ \& Eriksson JG 2007 Birth size, adult body composition and muscle strength in later life. International Journal of Obesity 31 1392-1399. (https://doi. org/10.1038/sj.ijo.0803612)

Zheng M, Lamb KE, Grimes C, Laws R, Bolton K, Ong KK \& Campbell K 2018 Rapid weight gain during infancy and subsequent adiposity: a systematic review and meta-analysis of evidence. Obesity Reviews 19 321-332. (https://doi.org/10.1111/obr.12632)

Zhao H, Song A, Zhang Y, Zhen Y, Song G \& Ma H 2018 The association between birth weight and the risk of type 2 diabetes mellitus: a systematic review and meta-analysis. Endocrine Journal 65 923-933. (https://doi.org/10.1507/endocrj.EJ18-0072)

Zimmet PZ, Magliano DJ, Herman WH \& Shaw JE 2014 Diabetes: a 21st century challenge. Lancet: Diabetes and Endocrinology 2 56-64. (https://doi.org/10.1016/S2213-8587(13)70112-8)

Zinman B, Wanner C, Lachin JM, Fitchett D, Bluhmki E, Hantel S, Mattheus M, Devins T, Johansen OE, Woerle HJ, et al. 2015 Empagliflozin, cardiovascular outcomes, and mortality in type 2 diabetes. New England Journal of Medicine 373 2117-2128. (https://doi. org/10.1056/NEJMoa1504720)

Received in final form 27 March 2019

Accepted 4 April 2019

Accepted Preprint published online 4 April 2019 (c) 2019 Society for Endocrinology Published by Bioscientifica Ltd. 